\title{
Small Nuclear Ribonucleoprotein Polypeptide N Accelerates Malignant Progression and Poor Prognosis in Colorectal Cancer Transcriptionally Regulated by E2F8
}

\author{
Meiling $\mathrm{Ji}^{\dagger}$, Li Ren ${ }^{\dagger}$, Yang Lv', Xinyuan Lao, Qingyang Feng, Wentao Tang, Aobo Zhuang, \\ Tianyu Liu, Peng Zheng and Jianmin Xu*
}

Department of General Surgery, Zhongshan Hospital Fudan University, Shanghai, China

OPEN ACCESS

Edited by:

Muzafar Ahmad Macha,

Islamic University of Science and

Technology, India

Reviewed by:

Baltasar Pérez Saborido,

Hospital Universitario Río

Hortega, Spain

Shalini Gautam,

Texas Biomedical Research Institute,

United States

${ }^{*}$ Correspondence:

Jianmin Xu

xujmin@aliyun.com

tThese authors have contributed equally to this work

Specialty section

This article was submitted to

Gastrointestinal Cancers,

a section of the journal

Frontiers in Oncology

Received: 12 May 2020 Accepted: 04 September 2020 Published: 02 November 2020

Citation:

Ji M, Ren L, Lv Y, Lao X, Feng $Q$

Tang W, Zhuang A, Liu T, Zheng P and

Xu J (2020) Small Nuclear

Ribonucleoprotein Polypeptide N

Accelerates Malignant Progression and Poor Prognosis in Colorectal Cancer Transcriptionally Regulated by E2F8. Front. Oncol. 10:561287. doi: 10.3389/fonc.2020.561287
Colorectal cancer is a major cause of death worldwide, and the identification of new diagnostic and prognostic biomarkers is crucial to develop new strategies to avoid colorectal cancer-related deaths. Small nuclear ribonucleoprotein polypeptide $\mathrm{N}$ (SNRPN) is an imprinted gene that plays an important role in various neurodevelopmental disabilities. In this study, SNRPN was highly expressed in colorectal cancer tissues and involved in the progression of this disease. Immunohistochemistry analysis of 1,310 colorectal cancer tissue samples showed that SNRPN highly expressed in cancer tissues than in adjacent tissues and was mainly localized in the nucleus. Clinical pathological factor analysis demonstrated that higher expression of SNRPN was significantly associated with larger tumor size, location of the tumor on the left-sided colon, neural invasion, and distant metastasis. Univariate and multivariate analyses showed that SNRPN expression was an independent risk factor for survival, with high expression levels indicating worse overall survival. Both in vitro and in vivo experiments confirmed that high expression of SNRPN was associated with tumor proliferation, cell cycle, and metastasis. Knocking down SNRPN blocked the cell cycle at the G2/M phase transition and promoted tumor cell apoptosis, inhibiting the progression of colorectal cancer. To explore the up-steam of SNRPN, we found by luciferase reporter assay and chromosomal immunoprecipitation assay that E2F8 was a transcriptional regulator up-steam of SNRPN in colorectal cancer. Systematic studies of SNRPN will help us discover new regulatory molecules and provide a theoretical basis for finding new molecular targets for this disease.

Keywords: colorectal cancer, SNRPN, proliferation, metastasis, E2F8

\section{INTRODUCTION}

Colorectal cancer (CRC) is one of three most common cancers both in the incidence and the mortality worldwide (1). As a gene-driven cancer, uncovering the molecular cascade from adenoma to cancer has greatly promoted the understanding of CRC tumorigenesis and development. Recently, with the use of targeted drugs and surgical treatment, the prognosis of the CRC patient has 
largely improved. However, the benefits to the overall population of patients with CRC are limited. To discover new molecular aspects and further explore the underlying molecular mechanisms are still important methods to improve early detection and prevention and can promote the development of innovative therapeutic strategies.

The small nuclear ribonucleoprotein polypeptide $\mathrm{N}$ (SNRPN) is an imprinted gene. It has been linked to various neurodevelopmental disorders in previous researches, for example, Angelman syndrome (AS), Prader-Willi syndrome (PWS), and autism spectrum disorders (ASDs) (2, 3). Li et al. demonstrated that the abnormal expression of SNRPN impairs neurological function through regulating the nuclear receptor subfamily, group A, member 1(Nr4a1) (4). SNRPN encodes an RNA-binding (SmN and Sm51) protein, SNRPN, which involved in pre-mRNA splicing, and it is one member of the small nuclear ribonucleic particle SMB/SMN family. SNRPN is responsible for splicing the calcitonin/CGRP transcript in the brain (5), and the alternative splicing also has been demonstrated due to the reduced expression levels of mature U2 snRNP. The expression of SNRPN is tissue specific, and the highest expression in adult is found in the heart and brain (6).

SNRPN is also known to be related to the onset of obesity, and the lack of SNRPN expression results in hyperphagia, loss of satiety, and obesity in PWS $(7,8)$. David et al. demonstrated that combination of three single-nucleotide polymorphisms (SNPs), rs12905653, rs1391516, and rs2047433, can predict the probability of obesity much better from a case-control study with a sample of 265 Spanish patients (9). SNRPN also plays a role in regulating osteoblastic differentiation of bone marrow-derived mesenchymal stem cells (BM-MSCs) by increasing runt-related transcription factor 2 (Runx2) expression at the RNA splicing level (10).

There are also some researches in cancers. Inactivation of the SNRPN gene results in lung and brain cancer $(11,12)$. Deletions of the SNRPN locus were discovered in gliomas and glioblastoma, selected as the down-regulated expressed gene (13). Increased CpG methylation was found in gastric cancer vs. non-metaplastic mucosa and showed a significant decreased expression in gastric cancer (14). SNRPN is a key player in pancreatic adenocarcinoma and medulloblastoma cell growth $(15,16)$. However, the role of SNRPN in CRC remains unknown. In this article, we investigated SNRPN expression levels in the tissues of CRC patients and their association with clinical prognosis. We also investigated the participation of SNRPN in the progression of CRC in vitro and in vivo, as well as the mechanism involved.

\section{MATERIALS AND METHODS}

\section{Study Patients}

A total of 1,310 consecutive CRC patients in Zhongshan Hospital Fudan University were recruited in the study retrospectively. The patients underwent radical primary tumor resections without prior treatment from 2008 to 2012. The stages of cancer were determined referring to the 8 th edition of the International Union Against Cancer (UICC)/American Joint Committee on Cancer (AJCC) TNM classification. The median follow-up time was 50.5 months. The ethical approval was given by the Clinical Research Ethics Committee of Zhongshan Hospital, Fudan University. Informed consent for the acquisition of tissue samples and clinical data was obtained from all patients.

\section{Immunohistochemistry}

Standard procedures were used to determine the levels of SNRPN expression in CRC tumor samples. After being dried overnight at $37^{\circ} \mathrm{C}$ and deparaffinized in xylene, the tissue microarray (TMA) slide was rehydrated through graded alcohol and then immersed in $3 \%$ hydrogen peroxide to block endogenous peroxidase activity. After that, it was antigen-retrieved with microwave heating. Then, slides were incubated with $10 \%$ normal goat serum at room temperature to reduce nonspecific reactions. The primary anti-SNRPN antibody produced in rabbit (SigmaAldrich Cat\# HPA003482, RRID: AB_1857337) and primary anti-E2F8 antibody produced in rabbit (LS bio cat\# RRID: LS-C804191) were diluted (1:100) in 3\% bovine serum albumin (BSA) with $1 \times$ phosphate-buffered saline (PBS) and incubated overnight. They were sequentially incubated with a polymer peroxidase-labeled secondary antibody at room temperature and then stained with 3,3'-diaminobenzidine (DAB).

\section{Evaluation of Immunohistochemistry}

The staining index of SNRPN was determined by multiplying the score of staining intensity with staining proportion. The score of intensity are as follows: $0=$ negative, $1=$ weak positive, 2 = moderate positive, and $3=$ strong positive. The area score was the percentage of positive cells among all tumor cells multiplied by 100 . Finally, the intensity score was multiplied by the area score, ranging from 0 to 300 . If the staining of sample was heterogeneous, each component region was scored independently and then summed. The immunohistochemistry (IHC) score was assessed by two pathologists independently.

\section{Lentivirus Packaging and Transduction}

The siRNA sequence targeting human SNRPN gene (NM_003097.5) was designed as follows: S1-GATCCGAATCTT CATTGGCACCTTTACTCGAGTAAAGGTGCCAATGAAGAT TCTTTTTG and S2-GATCCGTTCAGAAAGATCAAGCCAAA CTCGAGTTTGGCTTGATCTTTCTGAACTTTTTG. Both siRNAs were inserted into the vector pGp (SBI, USA), and the restriction enzyme sites were BamHI and EcoRI. HEK293T cells was transfected with the siRNA-harboring plasmid and two helper plasmids, pVSVG-I and pCMV $\Delta$ R8.92 (TIANGEN, China). Two days later, the cell culture media was obtained and then concentrated to get the recombinant lentivirus. The multiplicity of infection (MOI) of the recombinant lentivirus-containing media was 15 when added to the HCT116 cells.

\section{Quantitative Real-Time PCR}

Total cellular RNA was extracted through TRIzol reagent method (Life Technologies, USA). Then, RNA was reverse transcribed by PrimeScript RT Reagent Kit (TaKaRa, Japan). Real-time PCR was performed using SYBR master mixture (TaKaRa, Japan) on the Bio-Rad Connect Real-Time PCR 


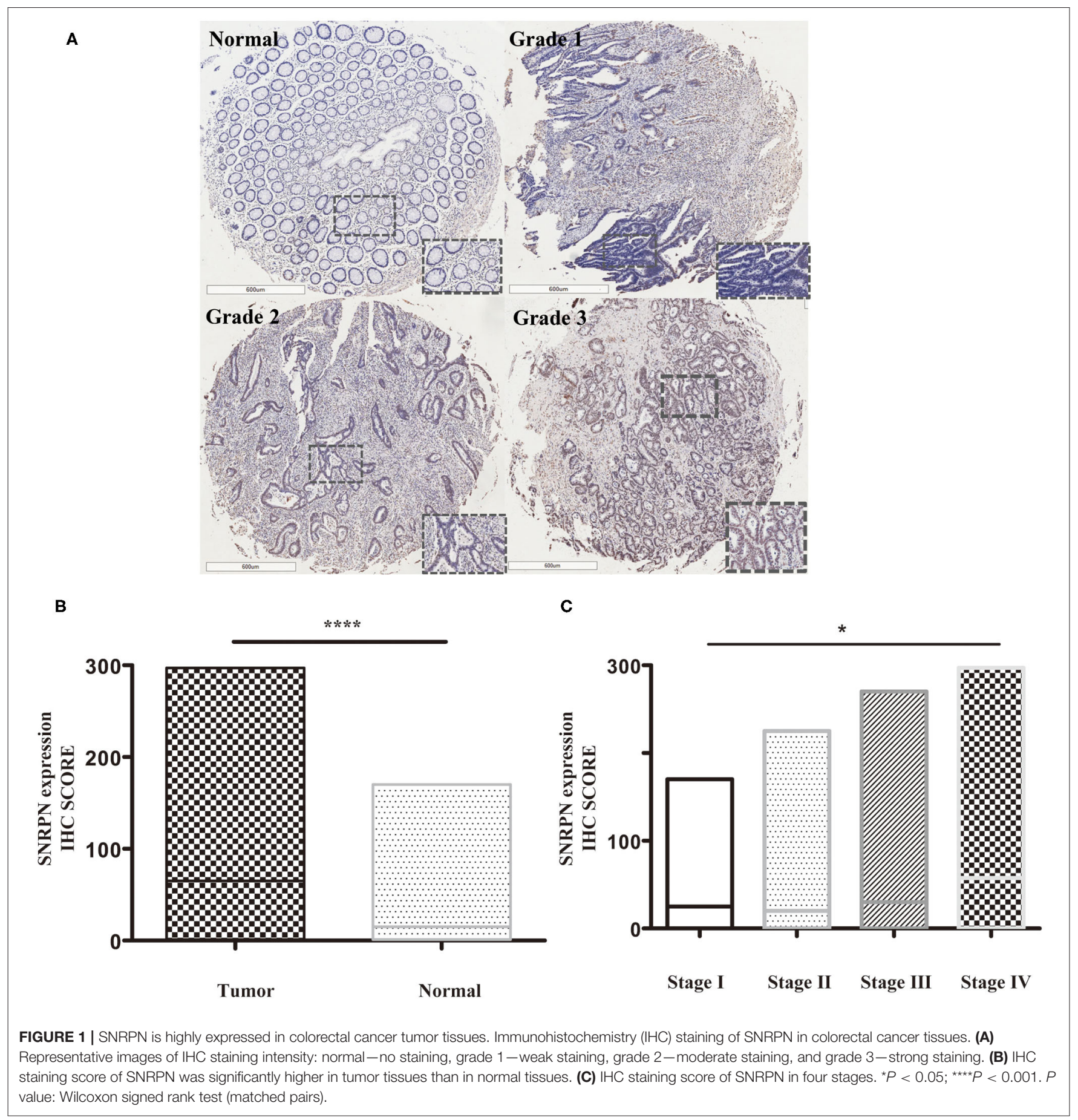

platform. The primer sequences of human SNRPN are as follows: 5' - GTTTTGGGTCTGGTGTTGCT-3' (forward) and $5^{\prime}$ - TCATTACCTGC TGGGA TGGT-3' (reverse). Comparative cycle threshold methods were used to calculate the relative quantities of mRNA normalized by ACTIN.

\section{MTT Assay}

Lentivirus-infected SW1116 and HCT116 cells were seeded in 96-well plates at an inoculation density of 2,500 and
3,000 cells/well, respectively. MTT (3-(4, 5-dimethylthiazol-2yl)-2, 5-diphenyltetrazolium bromide) solution was added when incubated on days 1 to 5 . The medium was then removed and acidic isopropanol (10\% sodium dodecyl sulfate (SDS), 5\% isopropanol, and $0.01 \mathrm{~mol} / \mathrm{l} \mathrm{HCl})$ was added. Plates were read at a wavelength of $595 \mathrm{~nm}$.

\section{Colony Formation Assay}

After lentivirus infection, SW1116 and HCT116 cells were seeded in six-well plates at a density of 200 cells/well. The medium was 
TABLE 1 | Relationship between SNRPN and clinical characteristics in included CRC patients.

\begin{tabular}{|c|c|c|c|c|}
\hline \multirow[t]{2}{*}{ Factors } & \multirow[t]{2}{*}{ Total } & \multicolumn{3}{|c|}{ SNRPN expression } \\
\hline & & Low & High & $P$ value \\
\hline All patients & 1,310 & 883 & 427 & \\
\hline Age (years) & & & & 0.325 \\
\hline$\geq 60$ & 728 (55.6\%) & 499 (56.6\%) & 229 (53.6\%) & \\
\hline$<60$ & 582 (44.4\%) & 384 (43.4\%) & 198 (46.4\%) & \\
\hline Gender & & & & 0.365 \\
\hline Male & 787 (60.6\%) & 538 (60.8\%) & 249 (58.3\%) & \\
\hline Female & 523 (40.0\%) & 345 (39.2\%) & 178 (41.7\%) & \\
\hline CEA (ng/ml) & & & & 0.628 \\
\hline$\leq 5$ & 689 (52.6\%) & 469 (53.2\%) & 220 (51.5\%) & \\
\hline$>5$ & 591 (45.1\%) & 392 (44.4\%) & 199 (46.6\%) & \\
\hline Unknown & $30(2.3 \%)$ & $22(2.4 \%)$ & $8(1.9 \%)$ & \\
\hline Tumor size (cm) & & & & 0.000 \\
\hline$\leq 5$ & 489 (37.3\%) & 368 (41.7\%) & $121(29.0 \%)$ & \\
\hline$>5$ & $821(62.7 \%)$ & 515 (58.3\%) & 306 (71.0\%) & \\
\hline Tumor differentiation & & & & 0.287 \\
\hline Well/moderate & $894(68.2 \%)$ & $611(69.18 \%)$ & $283(66.3 \%)$ & \\
\hline Poor/anaplastic & $416(31.8 \%)$ & $272(30.82 \%)$ & $144(33.7 \%)$ & \\
\hline Pathological type & & & & 0.329 \\
\hline Mucinous & $173(13.2 \%)$ & $111(12.6 \%)$ & $62(14.5 \%)$ & \\
\hline Non-mucinous & $1,137(86.8 \%)$ & 772 (87.4\%) & 365 (85.5\%) & \\
\hline Vascular invasion & & & & 0.904 \\
\hline No & $1,122(85.6 \%)$ & 757 (85.7\%) & 365 (85.5\%) & \\
\hline Yes & $188(14.4 \%)$ & 126 (14.3\%) & $62(14.5 \%)$ & \\
\hline Neural invasion & & & & 0.000 \\
\hline No & 1,214 & 855 (96.8\%) & 359 (84.1\%) & \\
\hline Yes & 96 & $28(3.2 \%)$ & 68 (15.9) & \\
\hline Tumor location & & & & 0.008 \\
\hline Right-sided colon & 364 (27.8\%) & $265(30.0 \%)$ & 99 (23.19\%) & \\
\hline Left-sided colon & 341 (26.0\%) & $211(23.9 \%)$ & $130(30.44 \%)$ & \\
\hline Rectum & 605 (46.2\%) & 407 (46.1\%) & 198 (46.37\%) & \\
\hline T stage & & & & 0.421 \\
\hline $\mathrm{T} 1 / \mathrm{T} 2$ & 237 (18.1\%) & $165(18.7 \%)$ & 72 (16.9\%) & \\
\hline $\mathrm{T} 3 / \mathrm{T} 4$ & 1,073 (81.9\%) & 718 (81.3\%) & 355 (83.1\%) & \\
\hline N stage & & & & 0.966 \\
\hline NO & 719 (54.9\%) & 485 (54.9\%) & 234 (54.8\%) & \\
\hline N1/N2 & 591 (45.1\%) & 398 (45.1\%) & 193 (45.2\%) & \\
\hline M stage & & & & 0.030 \\
\hline MO & 1,005 (76.7\%) & $693(78.5 \%)$ & $312(73.1 \%)$ & \\
\hline M1 & 305 (23.3\%) & 190 (21.5\%) & 115 (26.9\%) & \\
\hline
\end{tabular}

Bold emphasis has showed the significance of the values.

changed at 3-day intervals. After 8 days in 5\% CO2 incubator at $37^{\circ} \mathrm{C}$, cells were fixed by $4 \%$ paraformaldehyde and then stained with crystal violet solution.

\section{Transwell Assay}

After being trypsinized, cells were suspended in low serum media containing $0.1 \%$ fetal bovine serum (FBS) and seeded at $1 \times 10^{4}$ with $100 \mu \mathrm{l}$ on the upper chamber, and $500 \mu \mathrm{l}$ media with $10 \%$

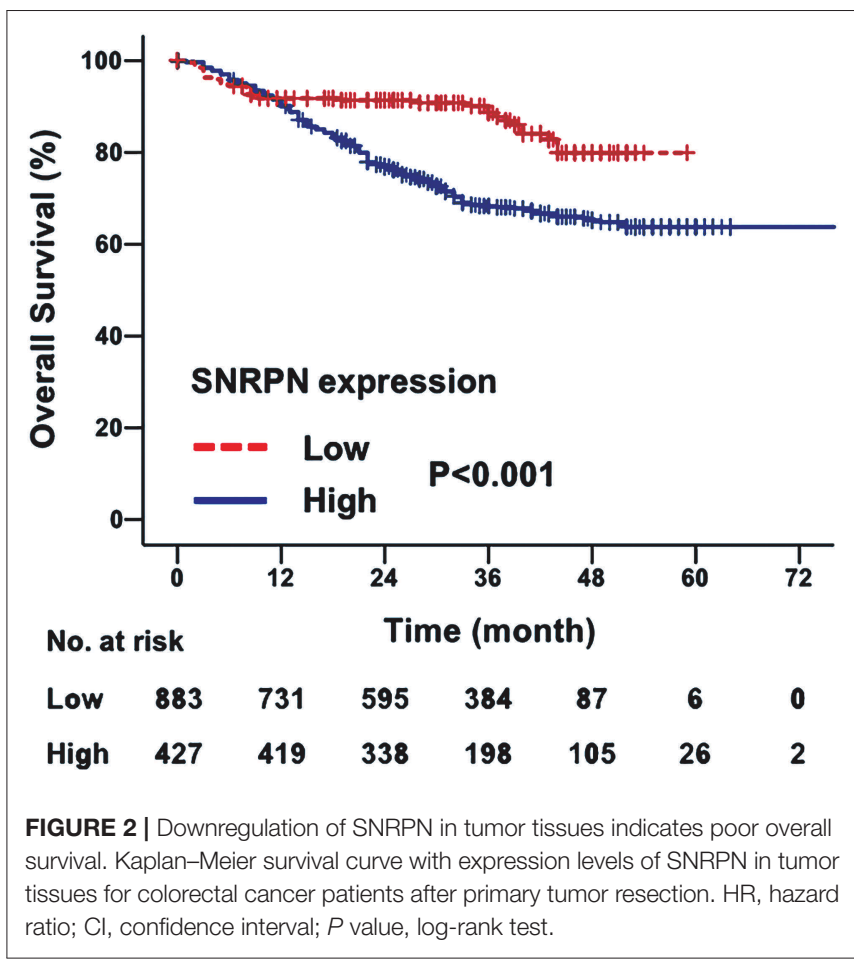

FBS (BD Biosciences, USA) was added to the lower chamber. After being cultured for $48 \mathrm{~h}$, the cells on the apical side of each insert were removed and washed with PBS. The invading cells were fixed with $4 \%$ paraformaldehyde for $30 \mathrm{~min}$ and stained by crystal violet. Invasion ability was assayed using the transwell experiment pre-cultured with Matrigel.

\section{Cell Cycle Assay}

SW 1116 cells were harvested and fixed in $75 \%$ ethanol at $4^{\circ} \mathrm{C}$ overnight and washed by PBS before resuspension in RNase A/propidium iodide solutions (Beyotime Biotechnology, China). After being incubated for $1 \mathrm{~h}$ at room temperature, stained cells were analyzed by flow cytometer (Beckman, Gallios, USA).

\section{Apoptosis Assay}

Cell apoptosis was assessed using an Annexin V/7-AAD double staining kit (KeyGen Biotech, China). Cells were harvested, proceeded following the manufacturer's protocol, and analyzed using a flow cytometer (Beckman, Gallios, USA).

\section{Western Blotting}

Cells were collected and lysed in $2 \times$ SDS sample buffer $(100 \mathrm{mM}$ Tris-HCl, pH 6.8; 10 mM EDTA; 4\% SDS; and 10\% glycine). Samples containing $30 \mu \mathrm{g}$ protein ran on SDS-PAGE gel at $80 \mathrm{~V}$. Proteins were then transferred to PVDF membrane at $300 \mathrm{~mA}$ for $90 \mathrm{~min}$. After being blocked by $1 \%$ BSA in TBS-T for $1 \mathrm{~h}$ at room temperature, the membrane was incubated with the primary antibodies overnight at $4^{\circ} \mathrm{C}$. After that, membranes were incubated with secondary antibodies at room temperature. The signals were determined by the enhanced chemiluminescence kit (Pierce, USA). 
TABLE 2 | Univariate and multivariate Cox regression analyses for overall survival.

\begin{tabular}{|c|c|c|c|c|}
\hline \multirow[t]{2}{*}{ Factors } & \multicolumn{2}{|c|}{ Univariate analysis } & \multicolumn{2}{|c|}{ Multivariate analysis } \\
\hline & HR (95\% Cl) & $P$ value & HR $(95 \% \mathrm{Cl})$ & $P$ value \\
\hline Age level & & 0.159 & & \\
\hline$\geq 60$ & 1 (reference) & & & \\
\hline$<60$ & $1.111(0.960-1.285)$ & & & \\
\hline Gender & & 0.948 & & \\
\hline Male & 1 (reference) & & & \\
\hline Female & 0.995 (0.859-1.153) & & & \\
\hline CEA (ng/l) & & 0.647 & & \\
\hline$\leq 5$ & 1 (reference) & & & \\
\hline$>5$ & $0.965(0.831-1.122)$ & & & \\
\hline Tumor location & & 0.699 & & \\
\hline Right-sided colon & 1 (reference) & & & \\
\hline Left-sided colon & $1.053(0.883-1.255)$ & & & \\
\hline Rectum & 0.965 (0.806-1.156) & & & \\
\hline Primary differentiation & & 0.009 & & 0.875 \\
\hline Well/moderate & 1 (reference) & & 1 (reference) & \\
\hline Poor/anaplastic & $1.243(1.057-1.463)$ & & $0.988(0.865-1.172)$ & \\
\hline Tumor size $(\mathrm{cm})$ & & 0.492 & & \\
\hline$\leq 5$ & 1 (reference) & & & \\
\hline$>5$ & $1.055(0.905-1.230)$ & & & \\
\hline Pathological type & & 0.263 & & \\
\hline Mucinous & 1 (reference) & & & \\
\hline Non-mucinous & $1.063(0.956-1.181)$ & & & \\
\hline Vascular invasion & & 0.141 & & \\
\hline No & 1 (reference) & & & \\
\hline Yes & $1.164(0.951-1.424)$ & & & \\
\hline Neural invasion & & 0.275 & & \\
\hline No & 1 (reference) & & & \\
\hline Yes & $1.024(0.632-2.851)$ & & & \\
\hline T stage & & 0.000 & & 0.035 \\
\hline $\mathrm{T} 1 / \mathrm{T} 2$ & 1 (reference) & & 1 (reference) & \\
\hline $\mathrm{T} 3 / \mathrm{T} 4$ & $1.941(1.523-2.243)$ & & $1.232(1.031-1.471)$ & \\
\hline N stage & & 0.000 & & 0.000 \\
\hline NO & 1 (reference) & & 1 (reference) & \\
\hline N1/N2 & $2.631(2.125-3.048)$ & & $2.312(2.010-2.678)$ & \\
\hline M stage & & 0.000 & & 0.000 \\
\hline MO & 1 (reference) & & 1 (reference) & \\
\hline M1 & 4.653 (3.891-5.563) & & $3.852(3.135-4.560)$ & \\
\hline SNRPN expression & & 0.000 & & 0.000 \\
\hline Low & 1 (reference) & & 1 (reference) & \\
\hline High & $2.086(1.749-2.446)$ & & $2.030(1.781-2.445)$ & \\
\hline
\end{tabular}

\section{In vivo Tumorigenic Assay}

Mice were injected subcutaneously with $8 \times 10^{6}$ SW1116 cells down-regulated SNRPN by lentivirus and its control group to establish a CRC tumorigenicity model. Animal experiments were performed with conformity to the guidelines for use of experimental animals. The male mice were obtained from the Shanghai SLAC Laboratory Animal Co. Ltd. Mice were sacrificed after 19 days, and subcutaneous tumors were collected. Tumor size was estimated by the maximum diameter of the tumor $(\mathrm{cm})$.

\section{Luciferase Reporter Assay}

E2F8 regulation on the activity of SNRPN promoter was determined by dual-luciferase reporter assay. Briefly, the promoter binding region of SNRPN was cloned in the pGL3Promoter Vector between Nhe I and Hind III downstream of the luciferase reporter. E2F8 was conducted in PEGFP-N1 vector between Hind III and BamH I. The vectors were cotransfected into HEK293T cells. At $48 \mathrm{~h}$ after transfection, we harvested the cells and measured the relative luciferase activity using Dual Luciferase Reporter assay system (Promega,USA). The luciferase activity was measured per 1,000 cells. The firefly luciferase activity/Renilla luciferase activity for each construct was compared with the pGL3-Basic vector control. All experiments were performed at least three times.

\section{Chromatin Immunoprecipitation Assays}

Chromatin immunoprecipitation (ChIP) was conducted as described on manual. Briefly, HEK293T cells were harvested and cross-linked with $1 \%$ formaldehyde and quenching was performed with glycine. After being sonicated into $200-1,000 \mathrm{bp}$ fragments, protein $\mathrm{G}$ agarose was added to the complex (antibody and chromatin), and the mixture was incubated at $4^{\circ} \mathrm{C}$ overnight. E2F8 antibody (Abcam Cat\# ab109596) was added to pull down DNA from formaldehyde cross-linked chromatin. Then, protein $\mathrm{G}$ agarose antibody/chromatin complexes were resuspended by wash buffer and centrifuged for collection. The protein/DNA complexes were cleaved to get free DNA. Finally, the purified DNA was quantified using qPCR and the primers are as follows:

SNRPN-F1:TGCTGGGATTACAAGTGTGAG;

SNRPN-R1:GCAAGGACTATGAACAGC;

SNRPN-F2:GTGCTGGGATTACAAGTGTG;

SNRPN-R2:AGCAAGGACTATGGAGACAG.

\section{Statistical Analysis}

SPSS statistical package was used to analyze clinical data. E2F8 and SNRPN expression between normal and cancer tissues was compared by paired Wilcoxon signed-rank test. The correlations between continuous valuables were analyzed using Spearman rank correlation test and $\chi^{2}$ test. Kaplan-Meier method was carried out to analyze OS, and the results were compared by log-rank test. Hazard ratio [HR, 95\% confidence interval (CI)] was conducted to express risk factors. Statistical significance was defined as a $P$ value $<0.05$. Three independent experiments were conducted for statistical analysis and $t$ test was performed.

\section{RESULTS}

\section{SNRPN Is Highly Expressed in CRC Tumor Tissues}

Expression levels of SNRPN were determined using IHC staining. The results show that the subcellular localization of SNRPN is in the nucleus and that the positive expression rate of SNRPN was $89.31 \%$. The scores of IHC in tumor tissues were significantly higher than in normal tissues $(P<0.001)$, suggesting the accumulated expression of SNRPN in CRC tissues (Figure 1B). Representative pictures of different expression patterns of SNRPN are shown in Figure 1A. As CRC staging 


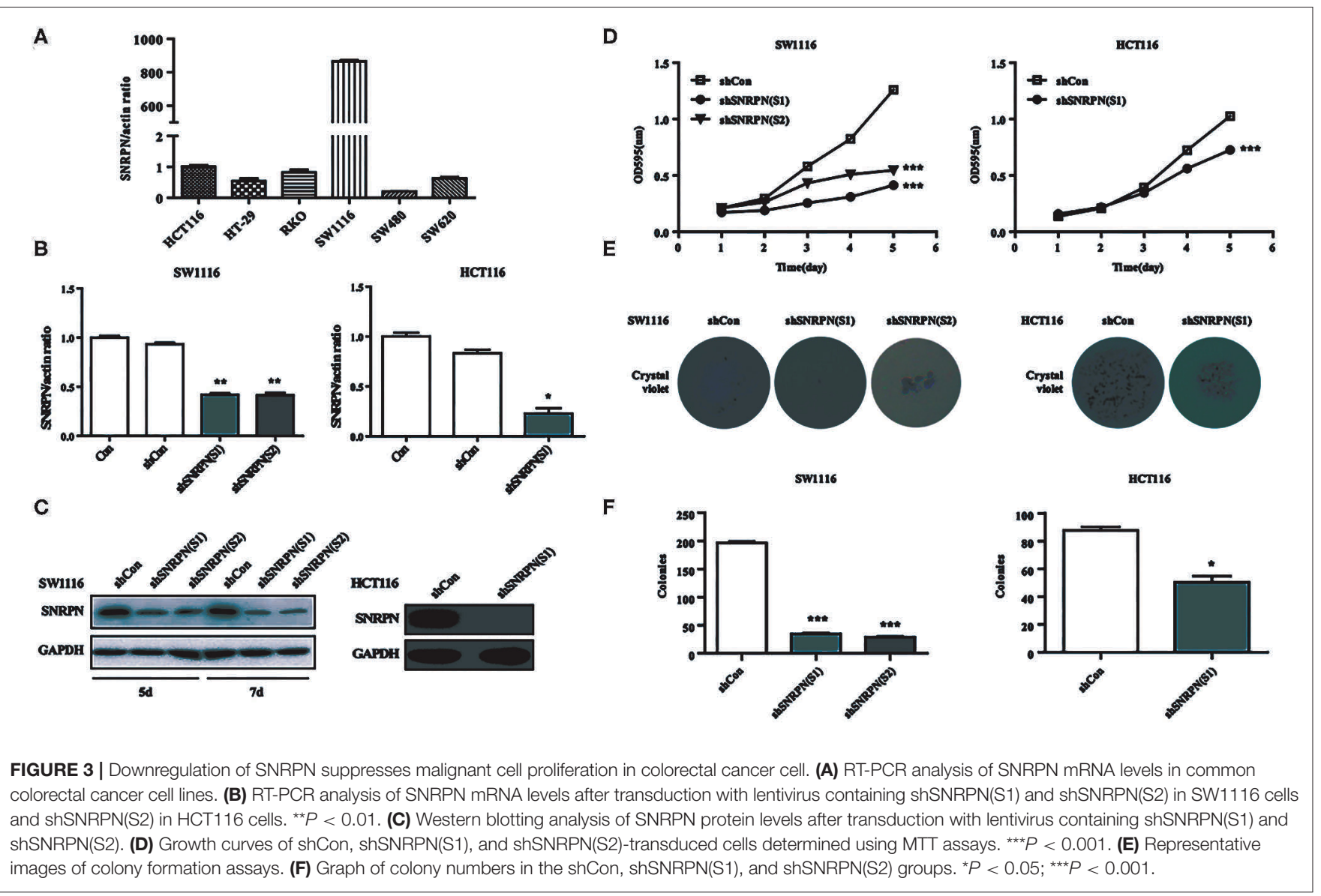

progressed, SNRPN expression increased: significantly different expression levels were observed when comparing stage IV with I (Figure 1C).

\section{The Association Between SNRPN Expression Levels and Clinical Characteristics}

In the study, samples with IHC scores between 5 and 9 were considered as high SNRPN expression, and IHC scores between 0 and 4 were considered as low expression. SNRPN was highly expressed in 427 samples and lowly expressed in 883 samples.

The association between SNRPN expression levels and the clinic-pathological characteristics of patients is shown in Table $\mathbf{1}$. Analysis demonstrates that higher expression of SNRPN was significantly associated with larger tumor size $(P=0.000)$, leftsided colon $(P=0.008)$, neural invasion $(P=0.000)$, and distant metastasis $(P=0.030)$.

\section{Higher Expression Levels of SNRPN Indicate Poorer Survival in CRC}

The median follow-up time for all patients was 31.0 months (ranging from 2 to 97 months). The overall survival of patients with highly expressed SNRPN was significantly worse than that of lowly expressed patients $(\mathrm{HR}=2.086,95 \% \mathrm{CI}=$ [1.749-2.446], $P<0.001)$. The 3- and 5-year OS rates were 67.3 and $62.2 \%$ for patients with high expression of SNRPN, respectively. For patients with low expression of SNRPN, the 3- and 5-year OS rates were 87.9 and $82.1 \%$ (Figure 2). These results suggest that high expression of SNRPN predicts worse OS.

To investigate the risk factors affecting the prognosis of CRC, univariate and multivariate analyses of prognosis were performed. Univariate analysis shows that primary tumor differentiation $(P=0.009)$, $\mathrm{T}$ stage $(P=0.000), \mathrm{N}$ stage $(P=0.000), \mathrm{M}$ stage $(P=0.000)$, and SNRPN expression levels $(P=0.000)$ were associated with survival outcomes significantly. In addition, multivariate Cox regression analyses showed that SNRPN expression was an independent prognostic factor of OS in CRC patients $(P=0.000, \mathrm{HR}=2.030,95 \%$ CI: $1.781-2.445)$ (Table 2).

\section{Downregulation of SNRPN Suppresses CRC Cell Proliferation}

To explore the biological function of SNRPN, we characterized it in cancer cells. Firstly, the basic expression of SNRPN in CRC cell lines was determined using qPCR, which shows higher expression levels in the SW1116 and HCT116 cell lines (Figure 3A). To further investigate the low expression 


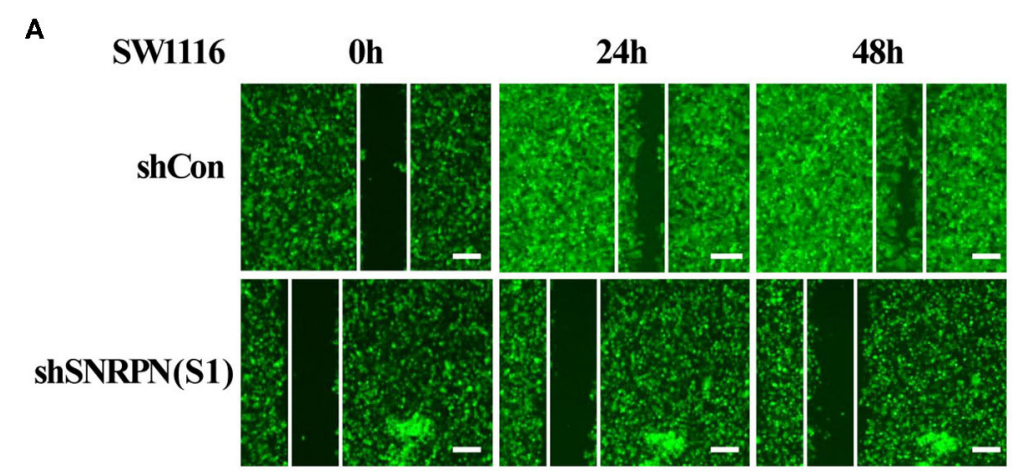

B
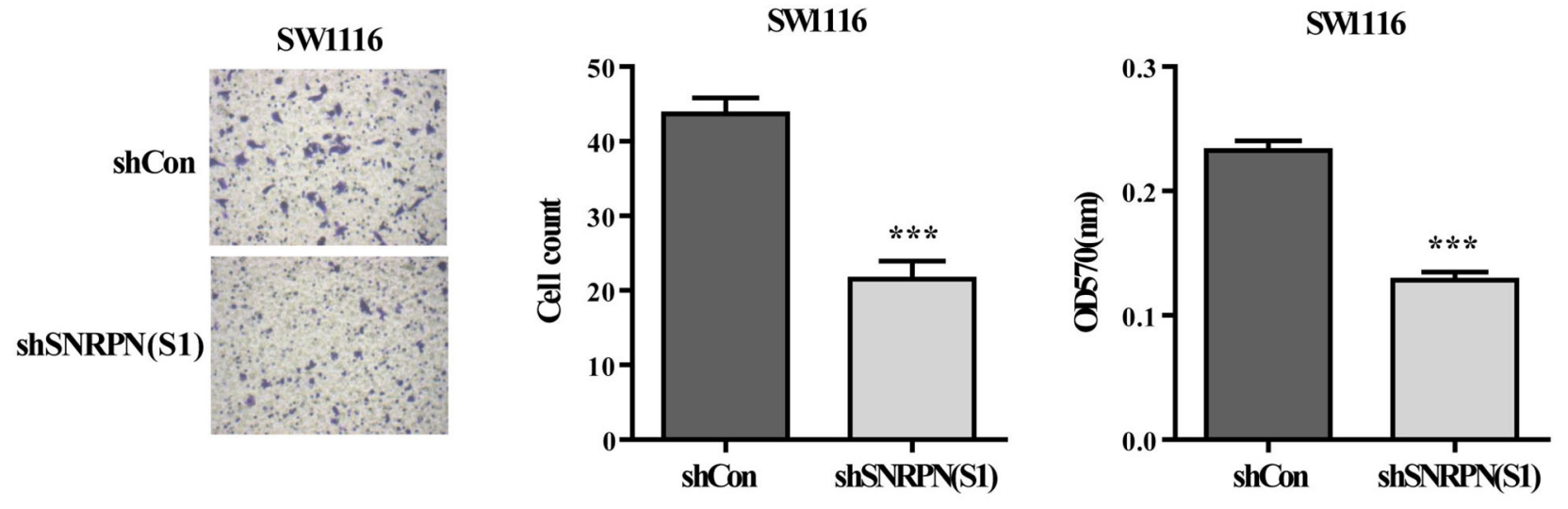

C

SW1116

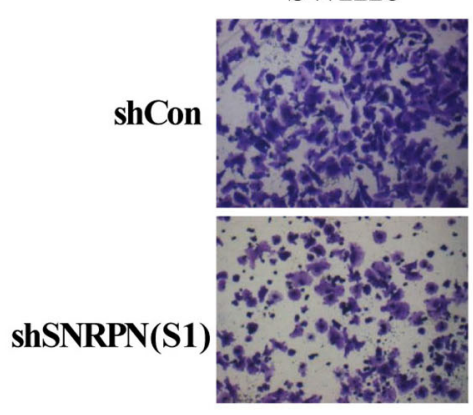

SW116
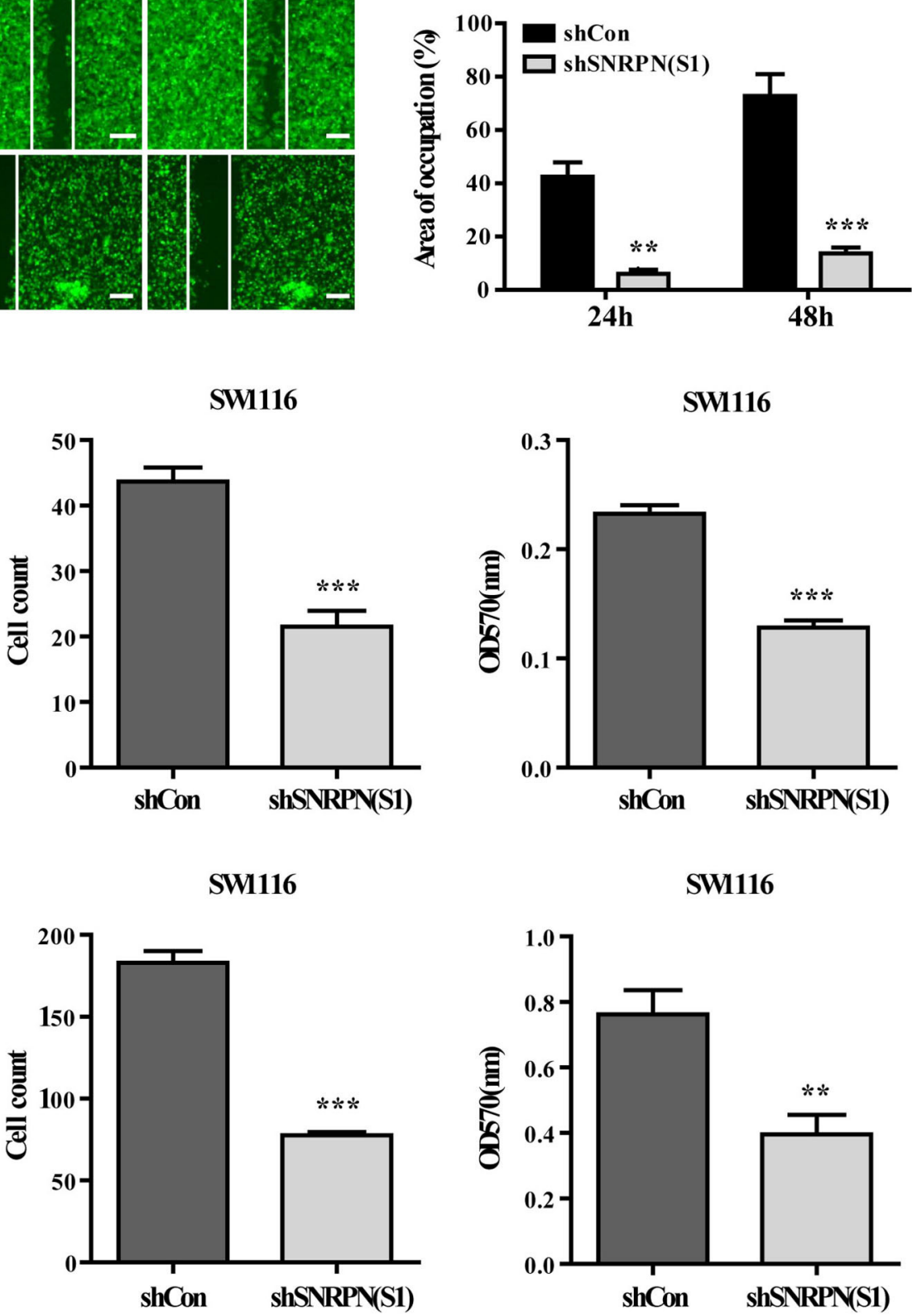

FIGURE 4 | Downregulation of SNRPN suppresses metastasis in colorectal cancer cells. (A) Wound healing experiment assays showing migration of SW1116 cells after downregulation of SNRPN. Area of occupation shown by representative images and graphs. ${ }^{\star \star} P<0.01$; ${ }^{\star \star \star} P<0.001$. (B) Migration assay of SW1116 cells after downregulation of SNRPN using transwell experiments. ${ }^{\star \star \star} P<0.001$. (C) Invasion assay of SW1116 cells after downregulation of SNRPN using transwell experiments with Matrigel. ${ }^{\star \star} P<0.01 ;{ }^{\star \star \star} P<0.001$.

of SNRPN in CRC, subsequent experiments employed these two cell lines. To eliminate off-target effects, we designed two shRNAs (S1 and S2) for different sequence segments of SNRPN and packed them into lentivirus. The results show that mRNA levels were effectively downregulated via shRNA(S1) and shRNA(S2) in SW1116 cells (Figure 3B). Western blotting results were consistent, and the downregulation of SNRPN in
SW1116 cells was to some extent time dependent (Figure 3C). To explore the biological function of SNRPN in CRC, we examined cell proliferation using MTT and colony formation assays. MTT assay results show that the proliferation of SW1116 cells was significantly inhibited by downregulation of SNRPN (Figure 3D). In addition, colony formation experiments were consistent with these results (Figures 3E,F). Because shRNA(S1) 
A

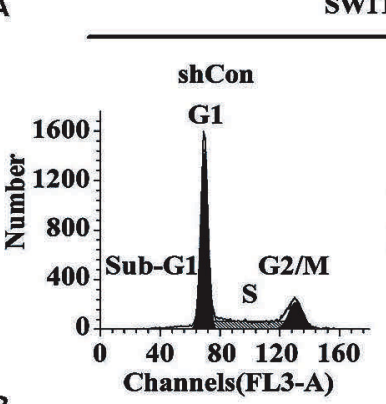

B

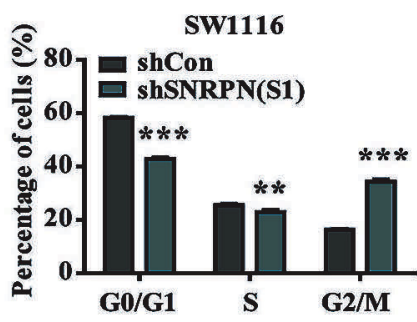

D

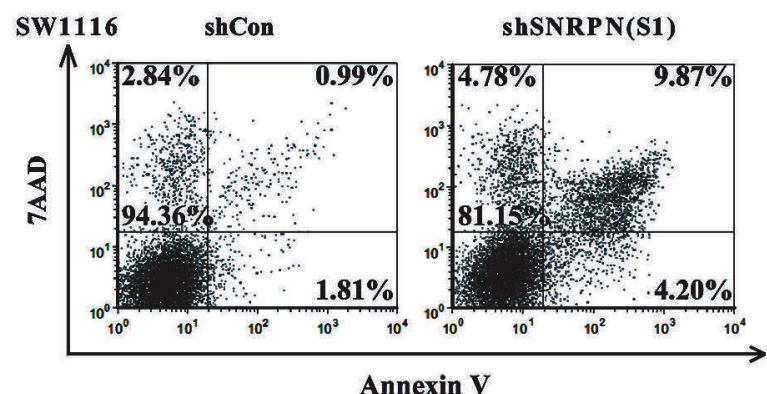

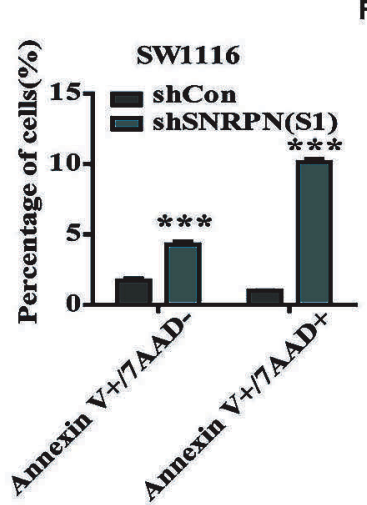

$\mathbf{F}$

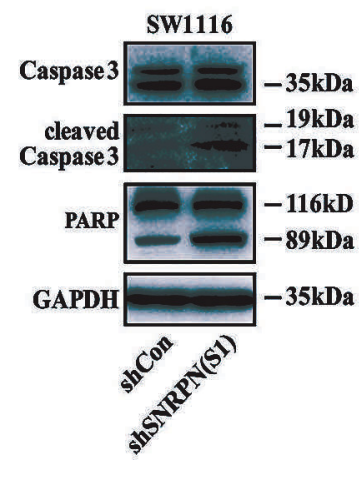

G

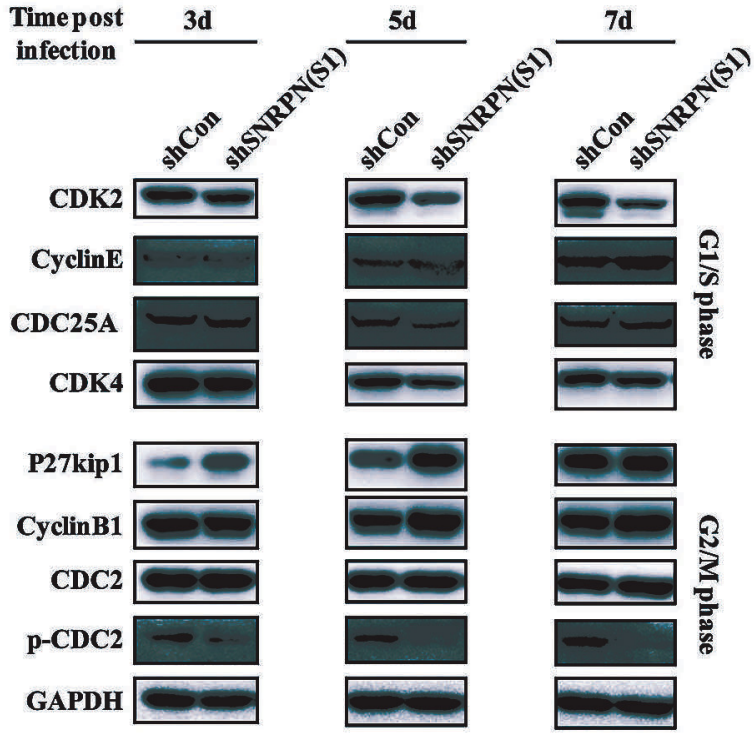

FIGURE 5 | SNRPN suppresses cell cycle and promotes apoptosis. (A) Representative picture of the cell cycle assayed using flow cytometry with PI staining. (B) Histogram of cell number in G0/G1, S, and G2/M phases. ${ }^{\star \star} P<0.01 ;{ }^{\star \star \star} P<0.001$. (C) Histogram of cell number in the sub G1 phase. (D) Representative picture of apoptosis assayed using flow cytometry with 7-ADD and Annexin $V$ double staining. (E) Percentage of apoptotic cells. (F) Western blotting analysis of apoptosis markers. (G) Western blotting analysis of markers involved in the cell cycle.

had a stronger interference effect, it was utilized to transduce HCT116 cells for further experiments. shRNA(S1) could effectively downregulate the expression of SNRPN in HCT116 cell lines at both the mRNA and protein levels. We conclude that cell proliferation is inhibited after SNRPN downregulation.

\section{Downregulation of SNRPN Suppresses CRC Cell Metastasis}

The effects of SNRPN on metastasis was also examined using wound healing assays. The results show that, when SNRPN was downregulated, the ability to heal decreased (Figure 4A). In addition, transwell experiments indicate a decreased migration ability (Figure 4B), and transwell experiments with Matrigel show a reduced invasive ability (Figure 4C).

\section{SNRPN Inhibits the Cell Cycle and Promotes Apoptosis}

To examine whether downregulation of SNRPN affects the cell cycle, flow cytometry was performed using PI staining. The results showed a decreased number of cell in the G0/G1 and $S$ phases and enrichment of cells in the G2/M phase compared to controls (Figures 5A,B). These results indicate an arrest in the G2/M phase transition after downregulation of SNRPN. In addition, the number of cells in the sub G1 phase increased, which suggests cell apoptosis after downregulation of SNRPN (Figure 5C). Apoptosis was detected using FCM with 7-aminoactinomycin D (7-ADD) and Annexin V double staining. The results show that the apoptosis rate was significantly increased, with $9.87 \%$ of apoptotic cells in the SNRPN downregulation group compared to only $0.99 \%$ in the control 
A

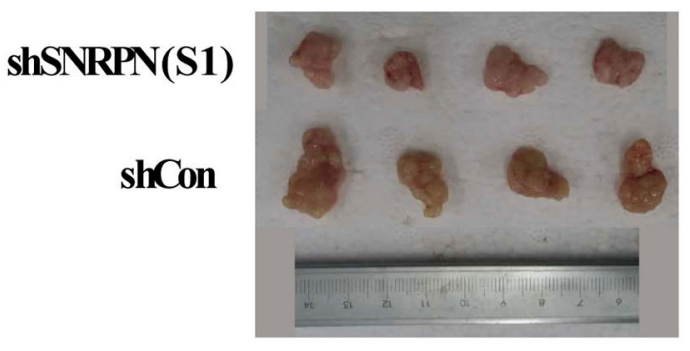

B

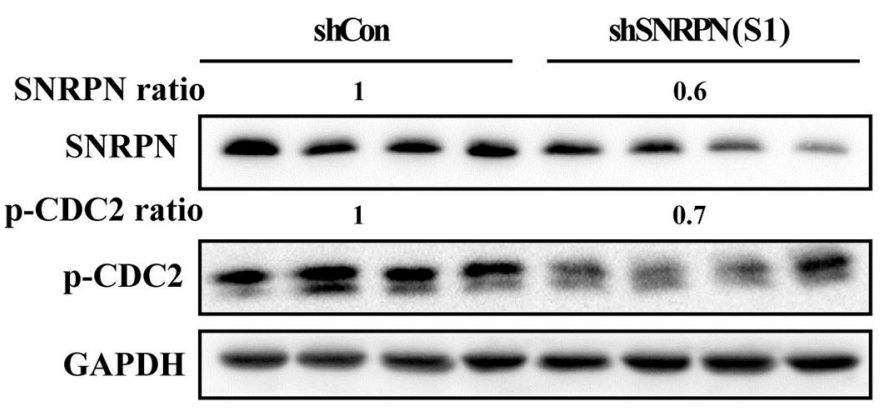

c

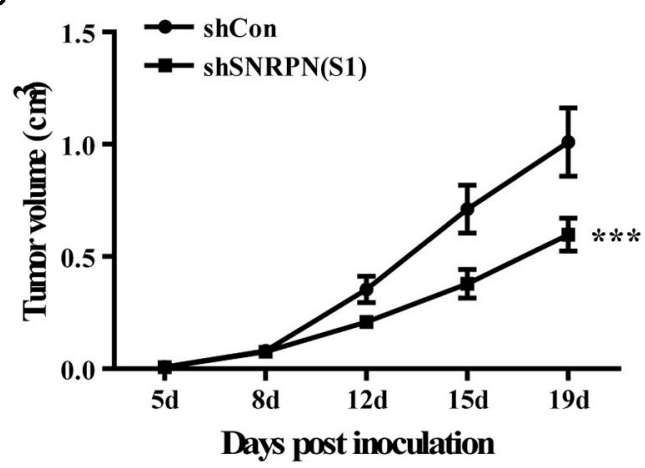

\section{SW1116}

Days post inoculation

IGURE 6 | Downregulation of SNRPN impairs growth of human colorectal cancer xenografts. (A) Effect of SNRPN on tumor formation in a nude mouse xenograft model. Pictures of tumors were taken after sacrifice on day 19. (B) Western blotting analysis of SNRPN and p-CDC2 expression levels. (C) The tumor size was smaller compared with the control group measured twice a week from day 5 after injection. ${ }^{\star \star \star} P<0.001$.

group (Figures 5D,E). In addition, Western blotting results show that the levels of cleaved caspase 3 and PAPR increased (Figure 5F). These results indicated that the absence of SNRPN results in apoptosis in CRC cells.

The mechanisms underlying the growth suppression by reduced SNRPN was investigated using Western blotting to determine the levels of molecular markers involved in the cell cycle 3, 5, and 7 days after transduction by lentivirus with shSNRPN. The results show that cyclin-dependent kinases CDK2 and CDK4 levels declined after 5 and 7 days, whereas cyclin E levels increased after 7 days, regulating the G1/S phase. In addition, P27kip1 levels were upregulated after 3 and 5 days, but restored after 7 days. The expression levels of another marker involved in the G2/M phase, $\mathrm{CDC} 2$, remained unaltered, although the levels of phosphorylated CDC2 decreased significantly (Figure 5G).

\section{Downregulation of SNRPN Impairs Growth of Human CRC Xenografts}

To determine the inhibition of cancer cell proliferation in vivo, we subcutaneously injected SW1116 cells transduced with shRNA(S1) and control cells into the left rear flank of Barb/c xenograft mice. Tumor size and body weight were measured twice a week. We found that low SNRPN expression significantly reduced tumorigenicity (Figure 6A). The tumor was found the first week after injection of cells, and its size was significantly smaller than that in the control group
(Figure 6C). Xenograft tissue was collected after 19 days of growth. The assessment of SNRPN and the cell cycle marker p-CDC2 shows that downregulation of SNRPN reduced the levels of $\mathrm{p}-\mathrm{CDC} 2$ and verified the cell cycle arrest in vivo (Figure 6B).

\section{E2F8 Is One of Transcriptional Regulators Up-Steam of SNRPN}

Recently, researches showed us abnormal methylation is one of the most important mechanisms for SNRPN, yet, we did not find the correlation of abnormally high expression of SNRPN and its methylation level in our study. To figure out the cause of high expression of SNRPN in CRC, we experimented to find possible up-steam regulators. Firstly, we found the promotor activity sequence by promotor 2.0 and predicted its possible binding transcript factor by database JASPAR. We then conducted the plasmids for luciferase reporter assay, and the results showed that the activity of the SNRPN $(2,500 \mathrm{bp})$ gene promoter was three times than that of its control group under the regulation of the E2F8 transcription factor (Figure 7A, $P<0.001$ ). This indicates that the E2F8 transcription factor can promote the SNRPN gene promoter. To further verify its endogenous binding, ChIP experiment was performed, and ChIP-qPCR indicated that E2F8 was a transcriptional regulator up-steam of SNRPN (Figure 7B). Besides, we found a positive correlation between the expression of E2F8 and SNRPN in patient tissues by the same set of tissue microarray (Figure 7C). In addition, it showed 


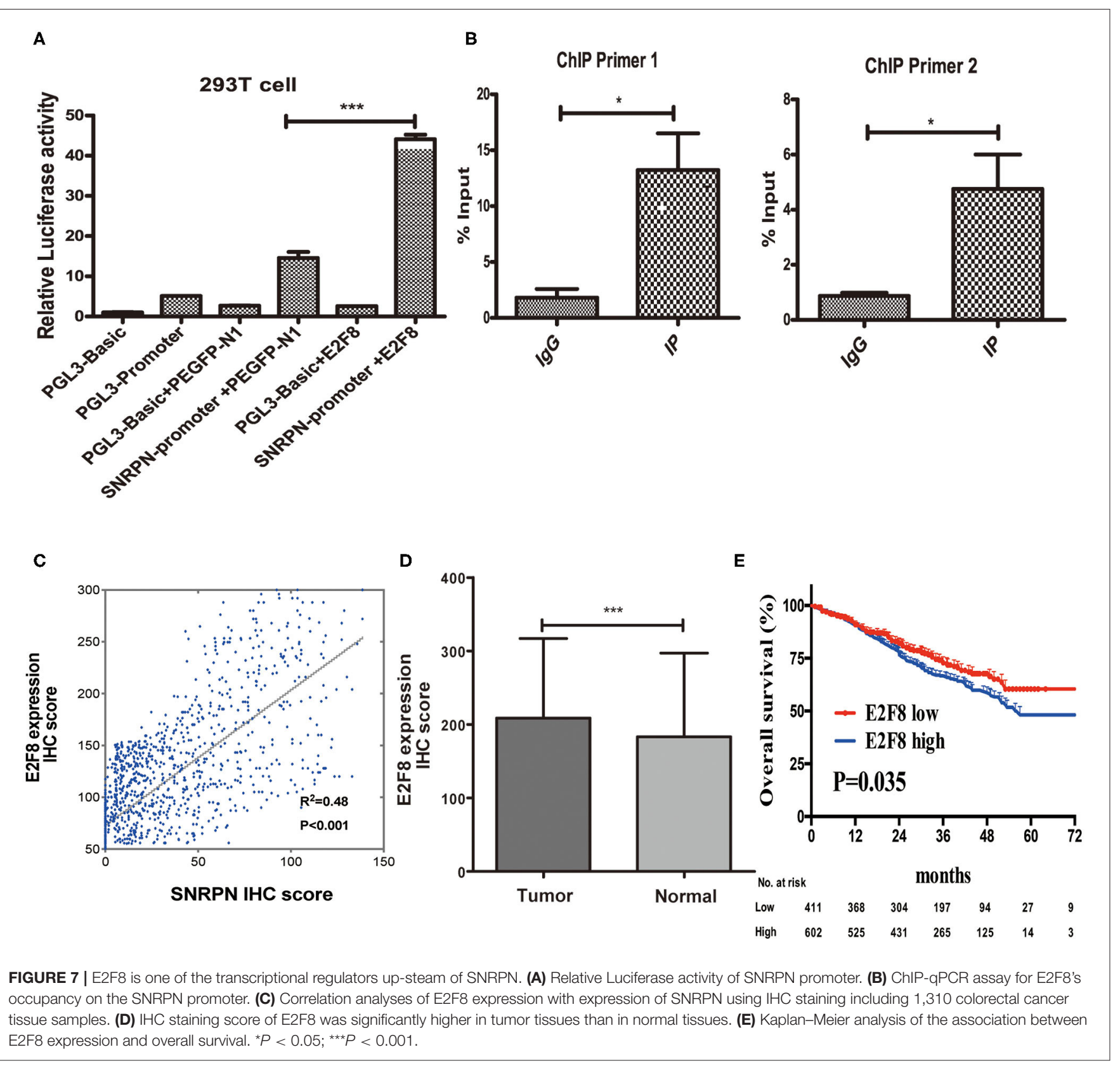

that IHC scores of E2F8 in tumor tissues were significantly higher than those in normal tissues (Figure 7D). The association between E2F8 expression levels and clinical characteristics is shown in Supplementary Table 1. Analysis demonstrated that the expression of E2F8 was significantly associated with gender, carcinoembryonic antigen (CEA) level, tumor differentiation, pathological type, vascular invasion, neural invasion, and distant metastasis. Increased expression of E2F8 was significantly associated with unfavorable OS in CRC (Figure 7E).

\section{DISCUSSION}

SNRPN is an imprinted gene for paternal expression and participates in the regulation of cell differentiation, cell proliferation, embryonic development, and mental behavior. It usually binds to a precursor RNA and thereby translates into different peptides by modulating alternate RNA splicing $(17,18)$. Until now, no studies on the participation of SNRPN in CRC have been described. In the present study, we found that SNRPN exhibits significantly increased expression levels in CRC tissues compared to adjacent normal tissues. Additionally, clinical and pathological data show that increased SNRPN expression is correlated with larger tumor size, tumor location on the leftsided colon, neural invasion, and distant metastasis. Moreover, patients with higher SNRPN expression levels had a poorer overall survival rate. These results indicate that the abnormal expression of SNRPN is associated with the development and progression of CRC. Further exploration of SNRPN biological 
function in CRC cells confirmed that the abnormal expression of SNRPN promotes the proliferation and metastasis of CRC cells and tumorigenicity.

Malignant proliferation is one of the hallmarks of cancer, and cell cycle plays an important role. Cell cycle progression depends on the activation of CDKs. In this study, we observed a time-dependent decrease in CDK4 and CDK2 levels and an increase in the levels of cyclin E, involved in the G0/G1 phase transition, after downregulation of SNRPN. In addition, an increase in cell arrest at the $\mathrm{G} 2 / \mathrm{M}$ phase resulted from upregulating P27Kip1, cyclin B1, and especially inactivity of CDC2. CDC2 plays a critical role in cell cycle inducing the G2/M transition and anti-mitosis. CDC2 is inactive in phosphorylated form, which induces the inactivation of the cyclin B/CDC2 complex and results in G2/M arrest $(19,20)$. Our study shows that SNRPN downregulation contributed to reduced CDC2 activity, ultimately leading to a G2/M cell cycle delay. In addition, an increase in the number of cells in the sub G1 phase indicates that SNRPN downregulation exhibits a strong anti-proliferative effect on CRC cells by promoting cell apoptosis.

Genomic imprinting is one important epigenetic phenomenon during gametogenesis, which accompanied DNA methylation of genes or gene clusters. This plays a major role in mammalian development, such as maintenance of chromatin structure and cell differentiation. CpG methylation is a central mechanism of epigenetic gene regulation and maintaining the imprinted state (21). Structurally, the SNRPN gene has $23 \mathrm{CpG}$ islets. Methylation is therefore an important mechanism of regulating SNRPN biological function.

SNRPN hyper-methylation was observed in some diseases, $34.9 \%$ in myelodysplastic syndrome and 50\% in acute myeloid leukemia (22). The methylation levels of SNRPN revealed statistical differences between adults and children, which indicates the role of SNRPN during the aging process (23). Differential methylation patterns of SNRPN have also been reported in multiple types of cancer. SNRPN methylation patterns in germ cell tumors reflect the primordial germ cell development (24). In gastric cancer, SNRPN acts as a novel hyper-methylated gene with corresponding reduced expression levels compared with intestinal metaplasia. In our study, the correlation of methylation and SNRPN expression levels in CRC had not been verified by TCGA data assay, but whether the high expression of SNRPN in CRC is mediated by abnormal methylation needs to be further explored.

To figure out the cause of high expression of SNRPN in $\mathrm{CRC}$, we explored the up-steam molecular regulator. Luciferase reporter assay and ChIP assay were employed to identify interactor of SNRPN; interestingly, we found E2F8 was one of the transcriptional regulators of SNRPN. E2F8 is a family member of the E2f transcription factors. It plays a crucial role in control of cell proliferation, differentiation, apoptosis, and gluconeogenesis $(25,26)$. Previous studies identified that the most significant biological process of E2F8 was regulating cell cycle $(27,28)$. Moreover, it was abnormally expressed in different kinds of cancers, such as hepatocellular carcinoma, lung cancer, cervical cancer, and papillary thyroid cancer. The mechanism was defined as oncogene by influencing cell cycle (29-32).
In CRC, E2F8 was highly expressed in cancer tissues and cell lines and a direct target of miR-1258 regulating cell cycle genes (33). Knockdown of E2F8 suppresses cell proliferation in colon cancer cells by modulating the NF-KB pathway (34). E2F8 acted as a stemness gene marker and was upregulated after celecoxib treatment in HT29 and DLD1 cells (35). In our study, we demonstrated that SNRPN was a target gene of E2F8, and increased expression of E2F8 induces high expression of SNRPN to regulate the malignant proliferation of cells by cell cycle regulation.

In conclusion, SNRPN was abnormally highly expressed in CRC tissues compared to adjacent normal tissues in 1,310 clinical samples, and its high expression was negatively associated with overall survival. Besides that, the loss of SNRPN expression in CRC cells decreased cell growth and metastasis, inhibited cell proliferation regulated by the cell cycle, and promoted apoptosis. The present study provides important evidence of the axis of E2F8/SNRPN in colorectal cancer.

\section{DATA AVAILABILITY STATEMENT}

The raw data supporting the conclusions of this article will be made available by the authors, without undue reservation.

\section{ETHICS STATEMENT}

The studies involving human participants were reviewed and approved by Clinical Research Ethics Committee of Zhongshan Hospital, Fudan University. The patients/participants provided their written informed consent to participate in this study. The animal study was reviewed and approved by Animal Ethics Committee of Zhongshan Hospital Fudan University.

\section{AUTHOR CONTRIBUTIONS}

MJ wrote the paper and completed the experiment. XL and JX designed the study. LR, YL, and QF contributed to the collection and analysis of clinical data. WT, AZ, TL, and PZ followed-up clinical data. All authors contributed to the article and approved the submitted version.

\section{FUNDING}

This study was supported by the National Natural Science Foundation of China (81472228 and 81702302), the National Key Research and Development Program of China (2017YF C0908200), and the Shanghai Science and Technology Committee Project (17411951300).

\section{SUPPLEMENTARY MATERIAL}

The Supplementary Material for this article can be found online at: https://www.frontiersin.org/articles/10.3389/fonc. 2020.561287/full\#supplementary-material 


\section{REFERENCES}

1. Siegel RL, Miller KD, Jemal A. Cancer statistics, 2020. CA Cancer J Clin. (2020) 70:7-30. doi: 10.3322/caac. 21590

2. Nicholls RD, Knepper JL. Genome organization, function, and imprinting in Prader-Willi and Angelman syndromes. Annu Rev Genomics Hum Genet. (2001) 2:153-75. doi: 10.1146/annurev.genom.2.1.153

3. Marshall CR, Noor A, Vincent JB, Lionel AC, Feuk L, Skaug J, et al. Structural variation of chromosomes in autism spectrum disorder. Am J Hum Genet. (2008) 82:477-88. doi: 10.1016/j.ajhg.2007.12.009

4. Li H, Zhao P, Xu Q, Shan S, Hu C, Qiu Z, et al. The autism-related gene SNRPN regulates cortical and spine development via controlling nuclear receptor Nr4a1. Sci Rep. (2016) 6:29878. doi: 10.1038/srep29878

5. Horn DA, Suburo A, Terenghi G, Hudson LD, Polak JM, Latchman DS. Expression of the tissue specific splicing protein $\mathrm{SmN}$ in neuronal cell lines and in regions of the brain with different splicing capacities. Brain Res Mol Brain Res. (1992) 16:13-19. doi: 10.1016/0169-328X(92)90188-H

6. Mcallister G, Amara SG, Lerner MR. Tissue-specific expression and cDNA cloning of small nuclear ribonucleoprotein-associated polypeptide N. Proc Natl Acad Sci USA. (1988) 85:5296-300. doi: 10.1073/pnas.85.14.5296

7. Bischof JM, Stewart CL, Wevrick R. Inactivation of the mouse Magel2 gene results in growth abnormalities similar to Prader-Willi syndrome. Hum Mol Genet. (2007) 16:2713-19. doi: 10.1093/hmg/ddm225

8. Horvath S, Erhart W, Brosch M, Ammerpohl O, Von Schonfels W, Ahrens M, et al. Obesity accelerates epigenetic aging of human liver. Proc Natl Acad Sci USA. (2014) 111:15538-43. doi: 10.1073/pnas.1412759111

9. Albuquerque D, Manco L, Gonzalez LM, Gervasini G, Benito GM, Gonzalez JR, et al. Polymorphisms in the SNRPN gene are associated with obesity susceptibility in a Spanish population. J Gene Med. (2017) 19:2956. doi: 10.1002/jgm.2956

10. Meng F, Xu L, Huang S, Liu Y, Hou Y, Wang K, et al. Small nuclear ribonucleoprotein polypeptide $\mathrm{N}$ (Sm51) promotes osteogenic differentiation of bone marrow mesenchymal stem cells by regulating Runx2. Cell Tissue Res. (2016) 366:155-62. doi: 10.1007/s00441-016-2411-0

11. Kondo M, Suzuki H, Ueda R, Osada H, Takagi K, Takahashi T, et al. Frequent loss of imprinting of the $\mathrm{H} 19$ gene is often associated with its overexpression in human lung cancers. Oncogene. (1995) 10:1193-8.

12. Korshunov A, Sycheva R, Golanov A. Recurrent cytogenetic aberrations in central neurocytomas and their biological relevance. Acta Neuropathol. (2007) 113:303-12. doi: 10.1007/s00401-006-0168-3

13. Vastrad B, Vastrad C, Godavarthi A, Chandrashekar R. Molecular mechanisms underlying gliomas and glioblastoma pathogenesis revealed by bioinformatics analysis of microarray data. Med Oncol. (2017) 34:182. doi: 10.1007/s12032-017-1043-x

14. Sepulveda JL, Gutierrez-Pajares JL, Luna A, Yao Y, Tobias JW, Thomas S, et al. High-definition CpG methylation of novel genes in gastric carcinogenesis identified by next-generation sequencing. Mod Pathol. (2016) 29:18293. doi: 10.1038/modpathol.2015.144

15. Jing J, Zhao Y, Wang C, Zhao Q, Liang Q, Wang S, et al. Effect of small nuclear ribonucleoprotein-associated polypeptide $\mathrm{N}$ on the proliferation of medulloblastoma cells. Mol Med Rep. (2015) 11:333743. doi: 10.3892/mmr.2015.3148

16. Ma J, Zhang Z, Wang J. Small nuclear ribonucleoprotein associated polypeptide $\mathrm{N}$ accelerates cell proliferation in pancreatic adenocarcinoma. Mol Med Rep. (2015) 12:6060-4. doi: 10.3892/mmr.2015.4208

17. Shemer R, Birger Y, Riggs AD, Razin A. Structure of the imprinted mouse Snrpn gene and establishment of its parental-specific methylation pattern. Proc Natl Acad Sci USA. (1997) 94:10267-72. doi: 10.1073/pnas.94.19.10267

18. Jin DK. Systematic review of the clinical and genetic aspects of Prader-Willi syndrome. Korean J Pediatr. (2011) 54:55-63. doi: 10.3345/kjp.2011.54.2.55

19. Pomerening JR, Sontag ED, Ferrell JEJr. Building a cell cycle oscillator: hysteresis and bistability in the activation of Cdc2. Nat Cell Biol. (2003) 5:346-51. doi: $10.1038 /$ ncb954
20. Choi HJ, Lim DY, Park JH. Induction of G1 and G2/M cell cycle arrests by the dietary compound 3,3'-diindolylmethane in HT-29 human colon cancer cells. BMC Gastroenterol. (2009) 9:39. doi: 10.1186/1471-230X-9-39

21. Kim MJ, Choi HW, Jang HJ, Chung HM, Arauzo-Bravo MJ, Scholer HR, et al. Conversion of genomic imprinting by reprogramming and redifferentiation. $J$ Cell Sci. (2013) 126:2516-24. doi: 10.1242/jcs.122754

22. Benetatos L, Hatzimichael E, Dasoula A, Dranitsaris G, Tsiara S, Syrrou M, et al. CpG methylation analysis of the MEG3 and SNRPN imprinted genes in acute myeloid leukemia and myelodysplastic syndromes. Leuk Res. (2010) 34:148-53. doi: 10.1016/j.leukres.2009.06.019

23. Carobin NV, Rubatino FV, Freitas ML, De Oliveira VT, Pietra RX, Bosco AA, et al. Methylation profile of SNRPN gene and its correlation with weight and chronological age. Genet Mol Res. (2015) 14:1379113798. doi: 10.4238/2015.October.28.41

24. Bussey KJ, Lawce HJ, Himoe E, Shu XO, Heerema NA, Perlman EJ, et al. SNRPN methylation patterns in germ cell tumors as a reflection of primordial germ cell development. Genes Chrom Cancer. (2001) 32:34252. doi: $10.1002 /$ gcc. 1199

25. Dimova DK, Dyson NJ. The E2F transcriptional network: old acquaintances with new faces. Oncogene. (2005) 24:2810-26. doi: 10.1038/sj.onc.1208612

26. Chen Y, Yu D, Wang L, Du S. Identification of E2F8 as a Transcriptional Regulator of Gluconeogenesis in Primary Mouse Hepatocytes. Biochem Biokhimiia. (2019) 84:1529-36. doi: 10.1134/S0006297919120125

27. Christensen J, Cloos P, Toftegaard U, Klinkenberg D, Bracken AP, Trinh $\mathrm{E}$, et al. Characterization of E2F8, a novel E2F-like cell-cycle regulated repressor of E2F-activated transcription. Nucleic Acids Res. (2005) 33:545870. doi: 10.1093/nar/gki855

28. Yuan R, Vos HR, Van Es RM, Chen J, Burgering BM, Westendorp B, et al. Chk1 and 14-3-3 proteins inhibit atypical E2Fs to prevent a permanent cell cycle arrest. EMBO J. (2018) 37:e97877. doi: 10.15252/embj.201797877

29. Park, S.-A., Platt J, Lee JW, López-Giráldez F, Herbst RS, et al. E2F8 as a novel therapeutic target for lung cancer. J Natl Cancer. (2015) 107:djv151. doi: 10.1093/jnci/djv151

30. Lv Y, Xiao J, Liu J, Xing F. E2F8 is a potential therapeutic target for hepatocellular carcinoma. J Cancer. (2017) 8:1205-13. doi: 10.7150/jca.18255

31. Sun J, Shi R, Zhao S, Li X, Lu S, Bu H, et al. E2F8, a direct target of miR-144, promotes papillary thyroid cancer progression via regulating cell cycle. $J$ Exp Clin Cancer Res. (2017) 36:40-. doi: 10.1186/s13046-017-0504-6

32. Kim LK, Park S-A, Eoh KJ, Heo T-H, Kim YT, Kim HJ. E2F8 regulates the proliferation and invasion through epithelial-mesenchymal transition in cervical cancer. Int J Biol Sci. (2020) 16:320-9. doi: 10.7150/ijbs.37686

33. Zhang Z, Li J, Huang Y, Peng W, Qian W, Gu J, et al. Upregulated miR-1258 regulates cell cycle and inhibits cell proliferation by directly targeting E2F8 in CRC. Cell Prolifer. (2018) 51:e12505. doi: 10.1111/cpr.12505

34. Yan P-Y, Zhang X-A. Knockdown of E2F8 suppresses cell proliferation in colon cancer cells by modulating the NF-кB pathway. Ann Clin Lab Sci. (2019) 49:474-80

35. Deng Y, Su Q, Mo J, Fu X, Zhang Y, Lin EH. Celecoxib downregulates CD133 expression through inhibition of the Wnt signaling pathway in colon cancer cells. Cancer Invest. (2013) 31:97-102. doi: 10.3109/07357907.2012. 754458

Conflict of Interest: The authors declare that the research was conducted in the absence of any commercial or financial relationships that could be construed as a potential conflict of interest.

Copyright (c) $2020 \mathrm{Ji}$, Ren, Lv, Lao, Feng, Tang, Zhuang, Liu, Zheng and Xu. This is an open-access article distributed under the terms of the Creative Commons Attribution License (CC BY). The use, distribution or reproduction in other forums is permitted, provided the original author(s) and the copyright owner(s) are credited and that the original publication in this journal is cited, in accordance with accepted academic practice. No use, distribution or reproduction is permitted which does not comply with these terms. 